\title{
Investigation of Best Operating Conditions for Treatment of Oily Wastewters with Hollow Fiber Ultrafiltartion Membranes
}

\author{
Mohsen Abbasi ${ }^{1, *}$ and Mohammad Reza Sebzari ${ }^{2}$ \\ ${ }^{1}$ Department of Chemical Engineering, School of Chemical and Petrolium Engineering, Persian Gulf \\ University, Bushehr, 75169, Iran \\ ${ }^{2}$ Department of Chemical Engineering, Lamerd Branch, Islamic Azad University, Lamerd, Iran
}

\begin{abstract}
This paper investigates the optimum operating conditions for treatment of oily wastewaters by application of UF process using the Taguchi method. The following operating conditions have been considered in this investigation: Back Wash time; Trans-membrane pressure (TMP); Flow rate and temperature. The optimum operating conditions of UF

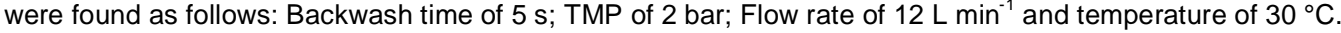

Experimental results presents that the importance level of the percentage contributions of each item is: (1) TMP (98.80 $\%)$, (2) back wash time (7.85\%), (3) flow rate (1.11\%), and (4) the feed temperature $(0.819 \%)$.
\end{abstract}

Keywords: Taguchi method, ultrafiltration, Oily wastewater treatment.

\section{INTRODUCTION}

Recently, huge amount of oily wastewaters are discharged into environment by oil and gas industry. Oily wastewaters have salt, hydrocarbons and toxic matters that can be have a dangerous effect on human and animal health [1-3]. For solving this problem, several separation processes for treatment of theses wastewaters by separation of oil have been investigated. In this area, operation such as: advanced oxidation processes, sedimentation, coagulation, flocculation, membrane processes, etc have been investigated by different researchers in literature [1, 2].

Nowadays, one of the best methods for treatment of oily wastewaters is membrane technology that has been investigated greatly in the recent years and is becoming a favorable process. This technology has benefits such as: high efficiency for oil separation, low fixed and operating costs and low volume requirement. Also, membrane technology has several advantages including: no requirement of chemical addition, treated wastewater with stable effluent quality [2-7].

Membrane fouling is a major obstacle for commercialization of the membrane processes for treatment of oily wastewaters. This can be reduced by optimizing the operating condition and choosing the right membrane. Therefore, This study focuses on the investigating the effects of back wash time, transmembrane pressure (TMP), temperature and volume

${ }^{*}$ Address correspondence to this author at the Department of Chemical Engineering, School of Chemical and Petrolium Engineering, Persian Gulf University, Bushehr, 75169, Iran; Tel: +98 (917) 323-9077; Fax: +98 (771) 4551838; E-mail: m.abbasi@mail.pgu.ac.ir flow rate (Q) on permeate flux of Hollow Fiber UF membranes for treatment of oily wastewaters.

The Taguchi method can significantly reduces the experimental costs by employing an orthogonal array that specially designed for the Taguchi method. Therefore, the best operating parameters can be achieved as presented by different researchers in literature for the area of wastewater treatment, ceramic preparation, solid fuel briquette, etc [7-14].

\section{EXPERIMENTAL}

\subsection{Membrane Specifications}

PAN-L1010 membrane module supplied by AMFOR Membrane Technology Company, was a kind of spiral wound membrane module has been employed in experiments. This commercial membrane has good performance (high permeability and high rejection rate of oil) during oily wastewater treatment. Table 1 lists the properties of this membrane.

Table 1: Properties of UF Membrane

\begin{tabular}{|c|c|}
\hline Membrane configuration & $\begin{array}{c}\text { Ultrafiltration } \\
\text { process }\end{array}$ \\
\hline Hollow Fiber \\
\hline \hline Surface area $\left(\mathrm{m}^{2}\right)$ & 0.7 \\
\hline Length $(\mathrm{m})$ & 0.5 \\
\hline MWCO $(\mathrm{kDa})$ & $100 \mathrm{kDa}$ \\
\hline TMP $(\mathrm{bar})$ & $1-2$ \\
\hline Maximum allowable temperature $\left({ }^{\circ} \mathrm{C}\right)$ & 50 \\
\hline Suitable operating range of $\mathrm{pH}$ & $3-10$ \\
\hline
\end{tabular}




\subsection{Oily Wastewater}

The produced oily wastewater in Sand Filter unit of Tehran refinery has been employed in experiments. The feed was taken daily from the refinery. Specifications of the wastewater has been presented in Table 2. The droplet size distribution of wastewater show that droplets diameter was below $20 \mu \mathrm{m}$ (see Figure 1). It must be noted that oil in water emulsion was stable during filtration experiments.

Table 2: Characteristics of the Oily Wastewater

\begin{tabular}{|c|c|c|}
\hline Item & Unit & Feed \\
\hline \hline TSS & $\mathrm{mg} / \mathrm{lit}$ & 92 \\
\hline Oil \& grease content & $\mathrm{mg} / \mathrm{lit}$ & 26 \\
\hline TOC & $\mathrm{mg} / \mathrm{lit}$ & 141 \\
\hline Turbudity & $\mathrm{mg} / \mathrm{lit}$ & 21 \\
\hline
\end{tabular}

\subsection{Setup}

To find the optimum operating parameters experiments were carried out in a pilot scale setup within 90 min operation. In setup, there were a heater and a coil of cooling water for adjusting the temperature. Also, each tank with a volume of $100 \mathrm{~L}$ and a thermostat in tank sets the temperature. Schematic of the setup has been shown in Figure 2. During experiments, retentate and permeate were continuously recirculated into the feed tank because by application of total recycle mode of filtration, the wastewater concentration in the tank remains fixed. Finally, the membranes were back flashed during the experiments by using hot water. More details of pilot plant have been presented in refrence1.

\subsection{Experimental Design}

The Taguchi method has been generally adopted to optimize the design parameters [7-14] because this

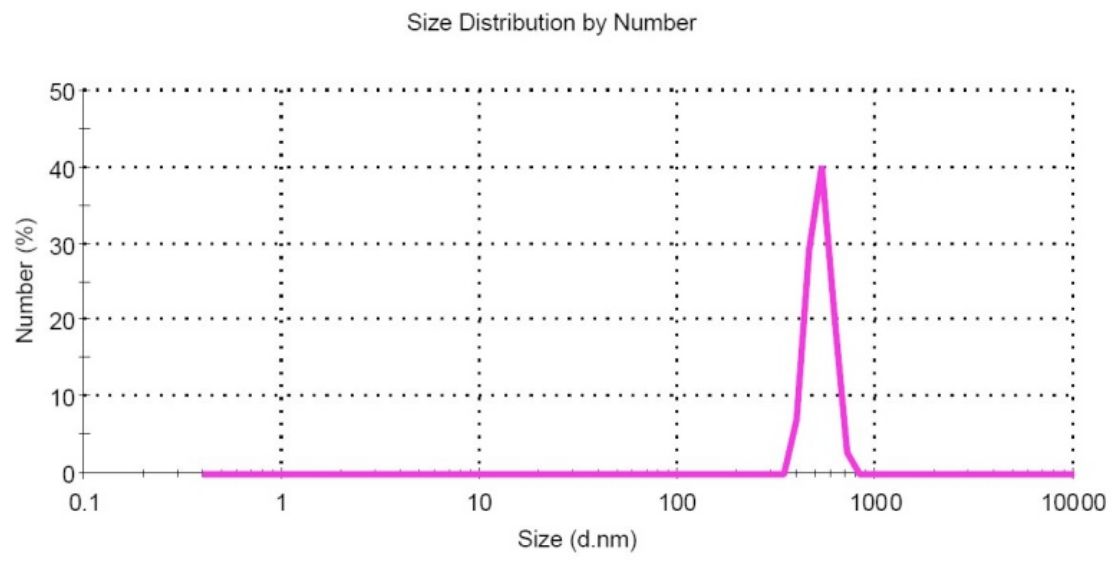

Figure 1: Droplet size distribution of oily wastewater.

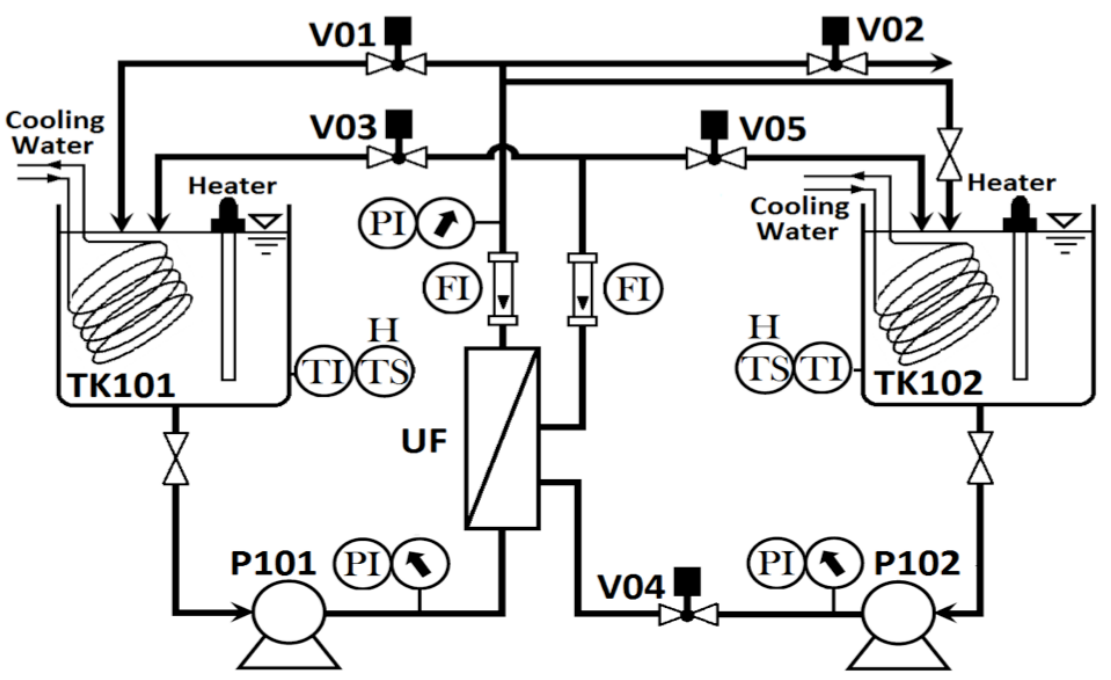

Figure 2: PFD of the experimental setup. 
systematic approach can significantly minimize the overall testing time and the experimental costs. Using the orthogonal array specially designed for the Taguchi method, the optimum experimental conditions can be easily determined.

In this research, for treatment of oily wastewater, four operating parameters have been selected and each operating parameter has three levels as shown in Table 3. Therefore, the test operating conditions can be arranged by using Table 3 and the L9 $\left(3^{4}\right)$ orthogonal array as presented in Table 4.

Table 4 presents the L9 $\left(3^{4}\right)$ orthogonal array of operating condition for Taguchi method and there is not permeation fluxes in this table. Backwash operation is used to removing of filter cake on the membrane surface.

The analysis of mean (ANOM) statistical approach is adopted herein to construct the optimal conditions. Initially, the mean of the $\mathrm{S} / \mathrm{N}$ ratio of each controllable factor at a certain level must be calculated. Therefore the optimal operating conditions were chosen as the highest average $\mathrm{S} / \mathrm{N}$ ratios $[14,15]$.

For evaluation of experimental results plus obtaining best operation conditions for treatment of oily wastewater an analysis of the signal-to-noise $(\mathrm{S} / \mathrm{N})$ ratio is applied as follows [14, 15]:

$\frac{S}{N}=-10 \log \left(\frac{1}{n} \sum_{i=1}^{n} \frac{1}{Y_{i}^{2}}\right)$

in the above equation, $\mathrm{n}$ is the number of repetitions under the similar experimental tests and $Y$ presents the permeation flux of membranes. To finding best operating parameters for treatment of oily wastewater, the average of the $S / N$ ratio of each operating parameter at a certain level is calculated as follows [14, 15]:

$(M)_{\text {Factor }=I}^{\text {Level }=i}=\frac{1}{n_{I i}} \sum_{j=1}^{n_{I i}}\left[\left(\frac{S}{N}\right)_{\text {Factor }=I}^{\text {Level }=i}\right]$

In Eq. (2), $n_{\text {li }}$ shows the number of appearances of factor I in the level i. Also, the parameter in sigma term is the $S / N$ ratio of factor I in level $i$, and its appearance sequence in Table $\mathbf{3}$ is the jth. In addition, the analysis of variance statistical method is also employed to investigate the effect of each operating parameter on the permeate flux. The percentage contribution of each factor $\left(\rho_{\mathrm{F}}\right)$, is calculated by the following formula [14, 15]:

Table 3: Operating Parameters and their Levels

\begin{tabular}{|c|c|c|c|c|}
\hline Factor & Description & Level 1 & Level 2 & Level 3 \\
\hline A & Back Wash time (t) s & 3 & 5 & 7 \\
\hline $\mathrm{B}$ & Trans-membrane pressure (TMP) bar & 1 & 2 & 3 \\
\hline $\mathrm{C}$ & Flow rate $(Q) \operatorname{Lmin}^{-1}$ & 8 & 12 & 16 \\
\hline $\mathrm{D}$ & Temperature $(\mathrm{T}){ }^{\circ} \mathrm{C}$ & 25 & 30 & 35 \\
\hline
\end{tabular}

Table 4: Test Conditions

\begin{tabular}{|c|c|c|c|c|}
\hline & $t(s)$ & TMP bar & $Q\left(\operatorname{Lmin}^{-1}\right)$ & $\mathbf{T}\left({ }^{\circ} \mathrm{C}\right)$ \\
\hline Test 1 & \multirow{3}{*}{3} & 1 & 8 & 25 \\
\hline Test 2 & & 2 & 12 & 30 \\
\hline Test 3 & & 3 & 16 & 35 \\
\hline Test 4 & \multirow{3}{*}{5} & 1 & 12 & 35 \\
\hline Test 5 & & 2 & 16 & 25 \\
\hline Test 6 & & 3 & 8 & 30 \\
\hline Test 7 & \multirow{3}{*}{7} & 1 & 16 & 30 \\
\hline Test 8 & & 2 & 8 & 35 \\
\hline Test 9 & & 3 & 12 & 25 \\
\hline
\end{tabular}


$\rho_{F}=\frac{S S F-\left(D O F_{F} V_{E r}\right)}{S S_{T}} \times 100$

In above formula, $\mathrm{DOF}_{\mathrm{F}}$ presents the degree of freedom for each factor. $\mathrm{SS}_{\mathrm{T}}$ is the total sum of squares and is calculated by this equation [14, 15]:

$S S_{T}=\sum_{j=1}^{m}\left(\sum_{i=1}^{n} Y_{i}^{2}\right)_{j}-m n\left(\bar{Y}_{T}\right)^{2}$

where

$\bar{Y}_{T}=\sum_{j=1}^{m}\left(\sum_{i=1}^{n} Y_{i}\right)_{j} /(m n)$ $m$ shows the experiments number and $\mathrm{n}$ is the number of repetitions under the similar experimental conditions. The factorial sum of squares, $\mathrm{SS}_{\mathrm{F}}$, is given by:

$S S_{F}=\frac{m n}{L} \sum_{k-1}^{L}\left(\bar{Y}_{k}^{F}-\bar{Y}_{T}\right)^{2}$

where $\mathrm{Y}_{\mathrm{k}}$ is the mean value of the measurement results of a certain factor in the $\mathrm{k}_{\mathrm{th}}$ level. In addition, the variance of error $\left(\mathrm{V}_{\mathrm{Er}}\right)$ can be calculated by the following equation [14, 15]:

$V_{E r}=\frac{S S_{T}-\sum_{F=A}^{D} S S_{F}}{m(n-1)}$

Table 5: The S/N Ratio of each Experiment Condition

\begin{tabular}{|c|c|c|c|}
\hline & \multicolumn{2}{|c|}{$\mathbf{Y}(\%)$} & \multirow{2}{*}{ S/N } \\
\cline { 2 - 4 } & $\mathbf{Y}_{1}$ & $\mathbf{Y}_{2}$ & 44.44106 \\
\hline \hline Test 1 & 167.4545 & 165.2474 & 45.61049 \\
\hline Test 2 & 191.2782 & 190.2345 & 45.57389 \\
\hline Test 3 & 190.4762 & 192.1652 & 44.65618 \\
\hline Test 4 & 171.4286 & 171.7624 & 45.56518 \\
\hline Test 5 & 190.2857 & 190.2978 & 45.42193 \\
\hline Test 6 & 187.1815 & 186.4532 & 44.83307 \\
\hline Test 7 & 174.9451 & 173.8766 & 45.34603 \\
\hline Test 8 & 185.5573 & 184.1223 & 45.7696 \\
\hline Test 9 & 194.8052 & 193.5411 & \\
\hline
\end{tabular}

Table 6: S/N Ratio Response Table

\begin{tabular}{|c|c|c|c|}
\hline \multirow[t]{2}{*}{ Factor/Level } & \multicolumn{2}{|c|}{$\left(\frac{S}{N}\right)_{\text {Factor }=I}^{\text {Level }=i}$} & \multirow[t]{2}{*}{$(M)_{\text {Factor }}^{\text {Level }}$} \\
\hline & $\mathrm{j}=1$ & $\mathrm{j}=2$ & \\
\hline$A / 1$ & 45.1872 & 45.13947 & 45.16327 \\
\hline $\mathrm{A} / 2$ & 45.29453 & 45.24743 & 45.27092 \\
\hline$A / 3$ & 45.19311 & 45.14545 & 45.16922 \\
\hline$B / 1$ & 44.62429 & 44.57344 & 44.59879 \\
\hline$B / 2$ & 45.56575 & 45.52014 & 45.54289 \\
\hline$B / 3$ & 45.4848 & 45.43877 & 45.46172 \\
\hline $\mathrm{C} / 1$ & 45.04891 & 45.00044 & 45.0246 \\
\hline $\mathrm{C} / 2$ & 45.32363 & 45.27666 & 45.30008 \\
\hline $\mathrm{C} / 3$ & 45.30231 & 45.25526 & 45.27872 \\
\hline $\mathrm{D} / 1$ & 45.26689 & 45.21965 & 45.24321 \\
\hline$D / 2$ & 45.23716 & 45.18969 & 45.21336 \\
\hline$D / 3$ & 45.1708 & 45.12302 & 45.14684 \\
\hline
\end{tabular}


Table 7: S/N Ratios in Test 9 and at the Best Operating Condition

\begin{tabular}{|c|c|c|c|c|c|c|c|}
\hline & A & B & C & D & $\mathbf{Y}_{\mathbf{1}}$ & $\mathbf{Y}_{\mathbf{2}}$ & S/N \\
\hline \hline Test 9 & 7 & 3 & 12 & 25 & 194.8052 & 193.5411 & 45.7696 \\
\hline Optimization condition & 5 & 2 & 12 & 25 & 199.1230 & 199.5432 & 45.98243 \\
\hline
\end{tabular}

Table 8: $\mathbf{Y}_{\mathbf{k}}$ for each Factor with Different Level

\begin{tabular}{|c|c|c|c|c|}
\hline & $\mathbf{Y}_{\mathbf{k}}{ }^{\mathbf{A}}$ & $\mathbf{Y}_{\mathbf{k}}{ }^{\mathbf{B}}$ & $\mathbf{Y}_{\mathbf{k}}{ }^{\mathbf{C}}$ & $\mathbf{Y}_{\mathbf{k}}{ }^{\mathbf{1}}$ \\
\hline \hline Level 1 & 182.5006 & 170.707 & 179.4954 & 183.6128 \\
\hline Level 2 & 182.4653 & 188.5404 & 185.3373 & 183.9682 \\
\hline Level 3 & 184.6025 & 190.321 & 184.7357 & 181.9874 \\
\hline
\end{tabular}

\section{RESULTS AND DISCUSSION}

Table 4 presents the L9 $\left(3^{4}\right)$ orthogonal array of operating condition for Taguchi method. The $\mathrm{S} / \mathrm{N}$ ratio of each test condition is determined by applying Eq. (1) has been presented in Table 5 in this table, the boldface is the maximum value of $\mathrm{S} / \mathrm{N}$ ratio in all experiment tests. Also, Table 6 presents the mean of the $S / N$ ratios of a certain factor in the $i_{\text {th }}$ level. It must be noted that in Table $\mathbf{6}$, the boldface is the maximum value of all data and thus it presents the best operating conditions for treatment of wastewater by hollow fiber UF membranes.

Based on results of Table 6, the optimum operating conditions of UF are as follows. (1) Backwash time of 5 $\mathrm{s}$; (2) TMP of 2 bar; (3) Flow rate of $12 \mathrm{~L} \mathrm{~min}^{-1}$ and (4) temperature of $30^{\circ} \mathrm{C}$.

Table 7 illustrates the $S / N$ ratio of registered permeate flux by using confirmed experiments at the best operating conditions.

The difference of the $\mathrm{S} / \mathrm{N}$ ratio between the best operating conditions and Test 9 is very small but the TMP decreases from 3 bar (in Test 9) to 2 bar (at the best operating conditions) and the duration of back wash decreases from $7 \mathrm{~s}$ (in Test 9) to $5 \mathrm{~s}$ (at the best operating conditions). It is obvious that employing filtration process with lower TMP, reduces operating costs for treatment of wastewater and also shorter back wash time have a positive effect on the total permeation flux of membrane.

Table 8 presents the $Y_{k}$ by employing results of Table 5. By replacing $Y_{k}$ and $Y_{T}=183.1895$ into Eq. (6), the $S S_{F}$ is calculated individually and these results have been listed in Table 9. Using Eq. (4), the $\mathrm{SS}_{\mathrm{T}}$, can be determined. By substituting $\mathrm{SS}_{\mathrm{F}}$ and $\mathrm{SS}_{\mathrm{T}}=$
1571.575 in the Eq. (7), $V_{E r}$ was obtained. In final, by the replacement of $\mathrm{SS}_{\mathrm{F}}, \mathrm{SS}_{\mathrm{T}}=1571.575, \mathrm{~V}_{\mathrm{Er}}=0.25$, and $\mathrm{DOF}_{\mathrm{F}}=2$ in the Eq. (3), the $\rho_{\mathrm{F}}$ was determined sequentially; and these results have been illustrated in Table 9.

Table 9: $\mathrm{SS}_{\mathrm{F}}$ and $\rho_{\mathrm{F}}$

\begin{tabular}{|c|c|c|}
\hline & SS $_{F}$ & $\boldsymbol{\rho}_{\mathrm{F}}$ \\
\hline \hline $\mathrm{A}$ & 123.90127 & 0.078521 \\
\hline $\mathrm{B}$ & 1411.814717 & 0.898026 \\
\hline $\mathrm{C}$ & 17.97448867 & 0.011119 \\
\hline $\mathrm{D}$ & 13.3844607 & 0.008198 \\
\hline
\end{tabular}

Based on the order of magnitudes of the operating conditions, the rank order of the percentage contributions of each factor is as follows: (1) TMP $(98.80 \%),(2)$ back wash time $(7.85 \%)$, (3) flow rate $(1.11 \%)$, and (4) the feed temperature $(0.819 \%)$. Therefore, it can be concluded that TMP is the most important parameter on permeation flux of membranes.

\section{CONCLUSIONS}

In this work, by employing the Taguchi method, the best operating conditions for treatment of oily wastewater in Sand Filter unit of Tehran refinery have been investigated. In addition, the percentage contribution of each operating parameter on the permeation flux of membranes was determined by the analysis of variance in a pilot scale plant.

Results showed that the beast operating conditions of UF are as follows:

(1) Backwash time of $5 \mathrm{~s}$;

(2) TMP of 2 bar; 
(3) Flow rate of $12 \mathrm{Lmin}^{-1}$ and

(4) temperature of $30^{\circ} \mathrm{C}$.

It was also found out that the shorter backwash time is more effective.

\section{REFERENCES}

[1] Hosein Abadi SR, Sebzari MR, Hemati M, Rekabdar F, Mohammadi T. Ceramic membrane performance. Desalination 2011; 265: 222-8. http://dx.doi.org/10.1016/j.desal.2010.07.055

[2] Cui J, Zhang X, Liu H, Liu S, Yeung KL. Preparation. J Membr Sci 2008; 325: 420-6. http://dx.doi.org/10.1016/j.memsci.2008.08.015

[3] Hua FL, Tsang YF, Wang YJ, Chan SY, Chua H, Sin SN. Performance. Chem Eng J 2007; 128: 169-5. http://dx.doi.org/10.1016/j.cej.2006.10.017

[4] Ebrahimi M, Willershausen D, Ashaghi KS, Engel L, Placido $\mathrm{L}$, Mund $\mathrm{P}$, Bolduan $\mathrm{P}$, Czermak $\mathrm{P}$. Investigations. Desalination 2010, 250: 991-6. http://dx.doi.org/10.1016/i.desal.2009.09.088

[5] Mohamed YT, Hussin LMS, Gad HMH, Daifullah AAM, AboEl-Enein SA. Membrane Stabilitiy. J Membr Sep Tecnol 2013; 2: 102-8.

[6] Jie $Y$, Dandan Z, Chao C, Hongxia G, Bangjun $H$, Yahong $\mathrm{H}$, Zhenao G, Shuren Y, Hong Y, Ziwei D, van Agtmaal S, Chunhui F. Pilot Scale. J Membr Sep Tecnol 2014; 3: 44-49.
[7] Tong G, Song J, Wang P, Zhao H, Tan X. Preparation. J Membr Sep Tecnol 2014; 3: 146-53.

[8] Wang SB, Pan C, Two-phase. Exp Thermal Fluid Sci 1998; 17: 189-201. http://dx.doi.org/10.1016/S0894-1777(98)00005-3

[9] Wu DH, Chang MS. Use. Materials Science and Engineering 2004; 379: 366-71. http://dx.doi.org/10.1016/j.msea.2004.03.006

[10] Chiang, KT. Optimization. Int Commun Heat Mass Transfer 2005; 32: 1193-201. http://dx.doi.org/10.1016/j.icheatmasstransfer.2005.05.015

[11] Erzurumlu T, Ozcelik B. Minimization. Mate Design 2006; 27: 853-61. http://dx.doi.org/10.1016/j.matdes.2005.03.017

[12] Wang TY, Huang CY. Improving. European J Operational Res 2007, 176: 1052-65. http://dx.doi.org/10.1016/j.ejor.2005.08.020

[13] Chou CS, Ho CY, Huang Cl. The optimum conditions. Adv Powder Technol 2009; 20: 55-61. http://dx.doi.org/10.1016/j.apt.2008.02.002

[14] Chou CS, Lin SH, Peng CC, Lu WC. The optimum conditions. Fuel Process Technol 2009; 90: 1041-46. http://dx.doi.org/10.1016/j.fuproc.2009.04.007

[15] Chou CS, Yang RY, Chen JH, Chou SW, The optimum conditions for preparing. Powder Technol 2010; 199: 264-71. http://dx.doi.org/10.1016/j.powtec.2010.01.015 